\title{
Clinical potential of bevacizumab in the treatment of metastatic and locally advanced cervical cancer: current evidence
}

This article was published in the following Dove Press journal:

OncoTargets and Therapy

16 May 2014

Number of times this article has been viewed

\section{Matthew W Jackson \\ Chad G Rusthoven \\ Christine M Fisher \\ Tracey E Schefter}

Department of Radiation

Oncology, University of Colorado,

Denver, CO, USA
Correspondence: Tracey E Schefter Department of Radiation Oncology, University of Colorado, 1665 Aurora Court, Suite 1032 MS F706, Aurora, Denver, CO 80045, USA

Email tracey.schefter@ucdenver.edu
Abstract: The addition of bevacizumab to established therapies for metastatic and locally advanced cervical cancer is an area of evolving research and a potential strategy toward improving historically suboptimal outcomes for women with advanced disease. Bevacizumab, when added to first-line chemotherapy, has now been shown to improve overall survival among women with metastatic cervical cancer, and recent Phase II data suggests it is safe and effective for patients with locally advanced disease treated with curative intent. Here we review the rationale and current evidence for bevacizumab in clinical practice, with an emphasis on the emerging role of bevacizumab in the treatment of metastatic and locally advanced cervical cancer.

Keywords: bevacizumab, Avastin ${ }^{\circledR}$, advanced cervical cancer, metastatic cervical cancer

\section{Introduction}

It is estimated that 12,340 women have been diagnosed with cervical cancer in the US in $2013^{1}$ and over 275,000 cases were estimated to be diagnosed worldwide in $2008 .^{2}$ Although modest strides have been made, cervical cancer remains the second most lethal cancer in women in developing countries. Of those diagnosed in the US, approximately one-third will die from the disease and this ratio is even worse in developing nations, where a greater percentage of women present with locally advanced or metastatic disease.

While both definitive surgery and radiation are effective in the treatment of earlystage cervical cancer, our ability to successfully manage patients with advanced disease remains suboptimal. In the $1990 \mathrm{~s}$, landmark trials established concurrent chemotherapy and radiotherapy as the standard of care for intermediate and locally advanced disease. ${ }^{3-5}$ More recently, in an attempt to improve outcomes beyond the optimization of standard radiation and cytotoxic chemotherapy, investigators have sought to add molecularly targeted biologic agents to the armamentarium of cervical cancer management, in both the metastatic and non-metastatic setting. One of the most promising and best studied of these molecular agents utilized to date is bevacizumab, a humanized monoclonal antibody against vascular endothelial growth factor A (VEGF-A). This review will address clinical experience with bevacizumab and the justification for its use, with an emphasis on the current evidence to support bevacizumab in the management of metastatic and locally advanced cervical cancer.

\section{Angiogenesis}

In the setting of malignancy, angiogenesis is a pathologic process by which tumors corrupt nearby vasculature, often resulting in the erratic formation of new blood vessels that 
promote neoplastic progression. Quantifiable surrogates for angiogenesis, such as microvessel density (MVD) and VEGF expression have been shown to be elevated in various solid tumors, ${ }^{6,7}$ including cervical cancer. ${ }^{8}$ Increased angiogenesis may also be a marker for enhanced biologic aggressiveness. In a series of 111 women with cervical cancer, high tumor MVD was a significant prognostic factor, and was associated with worse local control and diminished overall survival (OS) on multivariate analysis. ${ }^{9}$

The most well-studied angiogenic factor is VEGF, a member of a family of dimeric glycoproteins that play integral roles in the neogenesis of vascular and lymphatic channels, both developmental and pathologic. VEGF has been shown to trigger the proliferation of endothelial cells, regulate membrane permeability, and promote recruitment of stem cells to sites of neovascularization. ${ }^{10,11}$ These new blood vessels often lack pericytes, supportive cells that form alongside phenotypically normal vessels. As a result, malignant vasculature branches out in a haphazard, distorted manner, leading to functional abnormalities and ultimately resulting in leaky membranes, hemorrhage, and high interstitial pressure. ${ }^{6,12}$

The human papilloma virus (HPV) is the primary carcinogenic driver of cervical cancer worldwide, implicated in over $99 \%$ of cases. ${ }^{13}$ The oncogenic capability of this virus is due, in part, to stimulation of malignant neoangiogenesis. HPV infection, and subsequent incorporation of the pathogenic E6 oncoprotein, results in the degradation of the p53 tumor suppressor gene. Inactivation of p53 has numerous deleterious effects, one of which is unchecked proliferation of hypoxia inducible factor 1 (HIF-1), a transcription factor that helps stimulate neoangiogenesis mediated through VEGF and other gene products. Clinically, overexpression of HIF-1 has also been identified as a poor prognostic marker in cervical cancer. ${ }^{14}$ VEGF levels increase correspondingly with HIF-1 and are not downregulated by p53, as would be expected in healthy tissue. ${ }^{15,16}$ Levels of VEGF in tumors can be quantified using various immunohistochemistry (IHC) assays. Utilizing these IHC techniques to assess 73 cervical tumors after hysterectomy, Tokumo et al reported that elevated VEGF expression correlated well with MVD when evaluating the neovascularized regions of these tumor specimens. Further, these investigators also reported that MVD was significantly higher, and intensity of VEGF expression significantly stronger, in adenocarcinomas as compared to squamous cell carcinomas. ${ }^{17}$ This may contribute to the poorer outcomes observed for cervical adenocarcinomas when compared to squamous cell carcinomas. ${ }^{18}$ In a different study, Dobbs et al found that MVD and VEGF levels rose with progressively degenerative levels of cervical neoplasia, suggesting a direct correlation with neoplastic transformation. ${ }^{19}$ While normal tissue in these biopsy and hysterectomy specimens displayed relatively low levels of MVD and VEGF, these two parameters continued to increase proportionally to the grade of intraepithelial neoplasia and were at their highest levels in invasive carcinoma.

While VEGF signaling is known to play a vital role in both oncogenesis as well as normal human development, its activity within the physiologic milieu of an adult is thought to be minimal outside of normal wound healing. ${ }^{10}$ Thus, the inhibition of this process represents an attractive target to investigators hoping to realize an antitumoral effect while minimizing toxicity. This goal could potentially be achieved via administration of a number of molecularly targeted agents directed against VEGF and other key regulators of angiogenesis.

In the setting of recurrent and metastatic cervical cancer, tumors are often resistant to both chemo- and radiotherapy due to a variety of factors, including acquired treatment resistance, treatment-induced hypoxia and necrosis and, as some investigators have suggested, increased VEGF signaling. ${ }^{10}$ As a result, targeting angiogenesis has become an attractive investigational approach to these tumors. However, given the dependence of chemotherapy and radiation on functioning vasculature, concurrent treatment with an antiangiogenic agent such as bevacizumab would seem counterproductive to the desired therapeutic effect. In the simplest terms, chemotherapy is dependent on perfusion for delivery. Likewise, hypoxic tumors are known to respond poorly to both chemotherapy and radiation, with the generation of reactive oxygen species, in the case of radiation, being requisite to the induction of lethal DNA damage.

One leading hypothesis for bevacizumab's potential synergy with both chemotherapy and radiation is explained by the pruning or vessel normalization hypothesis, whereby anti-VEGF effects normalize the peritumoral vasculature to improve therapeutic efficacy. ${ }^{20,21}$ Instead of further hypoxia as one might expect, Lee et al demonstrated in their preclinical model that treatment with an anti-VEGF antibody can improve tumor oxygenation and act synergistically with radiation. ${ }^{22}$ A study of other antiangiogenic agents has also been reported, demonstrating the mitigation of hypoxia and enhancement of lethality induced by radiation. ${ }^{23}$ Clinical data to support this hypothesis was reported by Willett et al, who demonstrated that even an initial, low-dose $(5 \mathrm{mg} / \mathrm{kg})$ infusion of bevacizumab improved several parameters of aberrant, excessive perfusion and appropriately decreased vascular permeability, thereby returning the vasculature to 
a more normal state. ${ }^{24}$ While this normalization of vasculature may improve the delivery of chemotherapeutics and the tumor's sensitivity to radiation, it is unclear if these changes are transient or sustained. ${ }^{12}$ Regardless of the duration of susceptibility, restoration of the vasculature to a more normal phenotype may provide an open window of opportunity, during which the tumor is more susceptible to assault with concurrent delivery of chemotherapy or radiation.

\section{Reviewing the role of bevacizumab in non-cervical malignancies Bevacizumab for metastatic non-cervical malignancies}

When appraising the evolving role of bevacizumab for patients with cervical cancer, it is useful to consider the forerunning clinical experience with bevacizumab in other disease sites. Selected prospective Phase II and III trials evaluating bevacizumab in the metastatic and definitive setting in non-cervical malignancies are displayed in Table 1.

Some of the most important initial studies evaluated the role of bevacizumab in the setting of metastatic colorectal cancer. Hurwitz et al initially demonstrated a 4.7-month median OS benefit with the addition of bevacizumab to first-line chemotherapy for patients with previously untreated metastatic colorectal cancer. ${ }^{25}$ Three years later, another trial demonstrated a median OS benefit of 2.1 months when bevacizumab was added to second-line chemotherapy in previously treated patients with persistent metastatic disease. ${ }^{26}$ These trials led to US Food and Drug Administration (FDA) approval for bevacizumab in metastatic colorectal cancer as a first-line (2004) and second-line (2006) therapy.

Table I Selected prospective Phase II and III trials evaluating bevacizumab in non-cervical malignancies

\begin{tabular}{|c|c|c|c|c|c|c|}
\hline Study & $\mathbf{n}$ & Setting & Design & $\begin{array}{l}\text { Bevacizumab } \\
\text { dose }\end{array}$ & Toxicity with Bev & Outcomes with Bev \\
\hline Hurwitz et $\mathrm{al}^{25}$ & 813 & $\begin{array}{l}\text { Metastatic } \\
\text { colorectal }\end{array}$ & $\begin{array}{l}\text { Phase III. IFL +/- Bev } \\
\text { No previous palliative } \\
\text { chemo }\end{array}$ & $5 \mathrm{mg} / \mathrm{kg} \mathrm{q} \mathrm{l} 4 \mathrm{~d}$ & $\begin{array}{l}\text { G3 HTN more } \\
\text { common (I I \% versus } \\
\text { [vs] } 2 \%)\end{array}$ & Improved OS 20.3 vs 15.6 m \\
\hline $\begin{array}{l}\text { Giantonio } \\
\text { et } \mathrm{al}^{26}\end{array}$ & 829 & $\begin{array}{l}\text { Metastatic } \\
\text { colorectal }\end{array}$ & $\begin{array}{l}\text { Phase III. FOLFOX } 4+\text { - }- \\
\text { Bev or Bev alone } \\
\text { Previous palliative chemo }\end{array}$ & $10 \mathrm{mg} / \mathrm{kg}$ q $14 \mathrm{~d}$ & $\begin{array}{l}14 \% \text { increase in } \\
\text { G3/4 toxicities }\end{array}$ & Improved OS 12.9 vs 10.8 m \\
\hline Allegra et $\mathrm{al}^{36}$ & 2,672 & $\begin{array}{l}\text { Adjuvant } \\
\text { colorectal }\end{array}$ & Phase III. FOLFOX6 +/- Bev & $5 \mathrm{mg} / \mathrm{kg} \mathrm{q} 14 \mathrm{~d}$ & $\begin{array}{l}\text { More G3 HTN and } \\
\text { wound complications }\end{array}$ & No difference in DFS \\
\hline Willett et $\mathrm{al}^{34}$ & 32 & $\begin{array}{l}\text { Neoadjuvant } \\
\text { rectal }\end{array}$ & $\begin{array}{l}\text { Phase II. Fluorouracil- } \\
\text { Bev-RT }\end{array}$ & $5 \mathrm{mg} / \mathrm{kg} \mathrm{q} 14 \mathrm{~d}$ & $\begin{array}{l}\text { Diarrhea most } \\
\text { common G3 toxicity }\end{array}$ & $\begin{array}{l}5 \text { y LC and OS } 100 \% \\
5 \text { y PFS } 75 \%\end{array}$ \\
\hline Sandler et $\mathrm{al}^{27}$ & 878 & $\begin{array}{l}\text { Metastatic } \\
\text { NSCLC }\end{array}$ & $\begin{array}{l}\text { Phase III. Paclitaxel/ } \\
\text { carboplatin }+/- \text { Bev }\end{array}$ & $15 \mathrm{mg} / \mathrm{kg}$ q $21 \mathrm{~d}$ & $\begin{array}{l}\text { I5 TRDs in Bev } \\
\text { group, } 5 \text { pulmonary } \\
\text { hemorrhages }\end{array}$ & Improved OS 12.3 vs $10.3 \mathrm{~m}$ \\
\hline Miller et $\mathrm{al}^{28}$ & 673 & $\begin{array}{l}\text { Metastatic } \\
\text { breast }\end{array}$ & Phase III. Paclitaxel +/- Bev & $10 \mathrm{mg} / \mathrm{kg}$ q $14 \mathrm{~d}$ & $\begin{array}{l}\text { HTN more common. } \\
\text { No increased bleeding }\end{array}$ & PFS benefit (II.8 vs 5.9 m) \\
\hline Kindler et $\mathrm{al}^{29}$ & 535 & $\begin{array}{l}\text { Metastatic } \\
\text { pancreas }\end{array}$ & $\begin{array}{l}\text { Phase III. Gemcitabine } \\
+/- \text { Bev }\end{array}$ & $10 \mathrm{mg} / \mathrm{kg}$ q $14 \mathrm{~d}$ & $\begin{array}{l}\text { More G3/4 HTN and } \\
\text { proteinuria }\end{array}$ & $\begin{array}{l}\text { No significant difference } \\
\text { in PFS or OS }\end{array}$ \\
\hline Crane et $\mathrm{al}^{38}$ & 82 & $\begin{array}{l}\text { Adjuvant } \\
\text { pancreas }\end{array}$ & Phase II. Gemcitabine + Bev & $5 \mathrm{mg} / \mathrm{kg} \mathrm{q} \mathrm{l} 4 \mathrm{~d}$ & $35.4 \% \geq \mathrm{G} 3$ Gl toxicity & $\begin{array}{l}\text { Median I y OS II.9 m } \\
\text { Similar to historical } \\
\text { controls }\end{array}$ \\
\hline $\begin{array}{l}\text { Van Cutsem } \\
\text { et } \mathrm{al}^{30}\end{array}$ & 607 & $\begin{array}{l}\text { Metastatic } \\
\text { pancreas }\end{array}$ & $\begin{array}{l}\text { Phase III. Gemcitabine/ } \\
\text { erlotinib }+ \text { /- Bev }\end{array}$ & $5 \mathrm{mg} / \mathrm{kg} \mathrm{q} 14 \mathrm{~d}$ & $\begin{array}{l}\text { G3-5 toxicity relatively } \\
\text { balanced between } \\
\text { arms }\end{array}$ & $\begin{array}{l}\text { Improved PFS ( } 4.6 \text { vs } 3.6 \text { m) } \\
\text { No significant difference } \\
\text { in OS }\end{array}$ \\
\hline Gilbert et $\mathrm{al}^{40}$ & 637 & GBM & Phase III. TMZ/RT +/- Bev & $10 \mathrm{mg} / \mathrm{kg}$ q $14 \mathrm{~d}$ & $\begin{array}{l}\text { Increased } \geq \mathrm{G} 3 \mathrm{AEs}- \\
\mathrm{HTN} \text {, neutropenia, } \\
\text { TE, Gl perf }\end{array}$ & $\begin{array}{l}\text { Improved PFS (I0.7 vs } 7.3 \mathrm{~m} \text { ) } \\
\text { No difference in OS }\end{array}$ \\
\hline Chinot et $\mathrm{al}^{39}$ & 921 & GBM & Phase III. TMZ/RT +/- Bev & $10 \mathrm{mg} / \mathrm{kg}$ q $14 \mathrm{~d}$ & $\begin{array}{l}\text { More } \geq \mathrm{G} 3 \mathrm{AEs} \text { in } \\
\text { Bev arm }(67 \% \text { vs } 51 \%)\end{array}$ & $\begin{array}{l}\text { Improved PFS (I0.6 vs } 6.2 \mathrm{~m} \text { ) } \\
\text { No difference in OS }\end{array}$ \\
\hline Burger et $\mathrm{al}^{32}$ & 62 & $\begin{array}{l}\text { Advanced } \\
\text { ovarian }\end{array}$ & $\begin{array}{l}\text { Phase II. Bev monotherapy } \\
\text { I-2 prior cytotoxic } \\
\text { regimens }\end{array}$ & $15 \mathrm{mg} / \mathrm{kg}$ q $21 \mathrm{~d}$ & $\begin{array}{l}\text { HTN most common } \\
\text { G3 toxicity }\end{array}$ & $\begin{array}{l}\text { Median PFS } 4.7 \mathrm{~m} \\
\text { Median OS } 17 \mathrm{~m}\end{array}$ \\
\hline $\begin{array}{l}\text { Perren et } \mathrm{al}^{33} \\
(20 \mathrm{I} \mathrm{I})\end{array}$ & $\mathrm{I}, 528$ & $\begin{array}{l}\text { Advanced } \\
\text { ovarian }\end{array}$ & $\begin{array}{l}\text { Phase III. Carboplatin/ } \\
\text { paclitaxel }+ \text { /- Bev }\end{array}$ & $7.5 \mathrm{mg} / \mathrm{kg}$ q $21 \mathrm{~d}$ & $\begin{array}{l}\text { HTN much more } \\
\text { common with Bev }\end{array}$ & $\begin{array}{l}\text { Improved PFS } \\
\text { No significant OS benefit }\end{array}$ \\
\hline
\end{tabular}

Abbreviations: AEs, adverse events; Bev, bevacizumab; d, days; DFS, disease-free survival; FOLFOX, oxaliplatin, fluorouracil, and leucovorin; G, grade; GI perf: gastrointestinal perforation; GBM, glioblastoma multiforme; HTN, hypertension; IFL, irinotecan, bolus fluorouracil, and leucovorin; LC, local control; m, months; NSCLC, non small cell lung cancer; OS, overall survival; PFS, progression-free survival; q, every; RT, radiation therapy; TE, thromboembolic event; TRD, treatment-related death; TMZ, temozolamide; y, years; vs, versus. 
Additionally, bevacizumab prolonged survival in recurrent or advanced non-small-cell lung cancer. In the Eastern Cooperative Oncology Group (ECOG) 4599 study, Sandler et al demonstrated an OS benefit of 2 months (12.3 vs 10.3 months) when bevacizumab was added to paclitaxel and carboplatin for patients with Stage IIIB or IV disease. ${ }^{27}$ Notably, there were 15 treatment-related deaths in the bevacizumab arm of this trial, five secondary to pulmonary hemorrhage, while only two treatment-related deaths were observed in the control arm.

Conversely, the addition of bevacizumab has failed to generate survival advantages for metastatic disease when added to first-line chemotherapy at other sites, including metastatic breast ${ }^{28}$ or pancreatic cancer. ${ }^{29,30}$

Prior to the initial presentation of the results of the Gynecologic Oncology Group (GOG) 240 study, ${ }^{31}$ which is discussed in detail in the section entitled "Bevacizumab for cervical cancer", an OS advantage with bevacizumab had never been demonstrated in a gynecological malignancy. Similar to results seen in breast and pancreatic cancer, GOG 218 indicated that addition of bevacizumab during and as maintenance following carboplatin and paclitaxel lends a progression-free survival (PFS), but not an OS, benefit to women with newly diagnosed Stage III or IV ovarian cancer. ${ }^{32}$ A separate advanced and metastatic ovarian cancer trial, the International Collaboration on Ovarian Neoplasms (ICON7), enrolled predominantly low-risk women with no visible residual disease and included some women with high-risk, early-stage disease..$^{33}$ This trial also demonstrated a PFS benefit with a trend toward OS that did not reach statistical significance.

\section{Bevacizumab in the non-metastatic setting for non-cervical malignancies}

Other trials have demonstrated that bevacizumab may be safely combined with concurrent radiation as well as cytotoxic chemotherapy at standard doses in the potentially curative management of solid tumors, including rectal, pancreatic, and central nervous system primaries. When reviewing the use of bevacizumab in cervical cancer, it is useful to consider the toxicities observed with bevacizumab in addition to standard adjuvant therapy for other pelvic malignancies such as rectal cancer, as the definitive treatment of both sites necessitates irradiation of the pelvis. In the setting of locally advanced rectal cancer, Willett et al first demonstrated the safety of bevacizumab at $5 \mathrm{mg} / \mathrm{kg}$ intravenously alone and in combination with concurrent 5-fluorouracil and external beam radiation in the neoadjuvant setting. Dose escalation to $10 \mathrm{mg} / \mathrm{kg}$ of bevacizumab was halted as two of the initial five patients developed dose-limiting diarrhea and colitis during the combined modality phase of treatment. ${ }^{34}$ Although subsequent Phase II efficacy data in this small population was encouraging, ${ }^{35}$ perhaps just as pivotal was the evidence for bevacizumab's ability to promote vessel "normalization" within the tumor, ${ }^{24}$ potentially providing an opportunity for synergism with chemotherapy and radiation, the former a result of improved delivery and the latter a result of improved tumor oxygenation.

For colorectal cancer, Phase III trials in the adjuvant setting have been unable to confer an OS advantage. The National Surgical Adjuvant Breast and Bowel Project (NSABP) C-08 study, in which patients with Stage II or III colon cancer were randomized to 5-fluorouracil, leucovorin, and oxaliplatin (FOLFOX) plus or minus bevacizumab, failed to demonstrate a disease-free or OS benefit with the addition of bevacizumab; ${ }^{36}$ a result that was particularly disappointing in light of the aforementioned survival benefits observed in both the first- and second-line metastatic setting. ${ }^{25,26}$

In the setting of locally advanced pancreatic cancer, investigators from MD Anderson Cancer Center reported the safety outcomes and toxicity profile of bevacizumab in combination with concurrent capecitabine and abdominal radiation in a Phase I trial. ${ }^{37}$ The subsequent Phase II Radiation Therapy Oncology Group (RTOG) 0411 study, was the first prospective, multi-institutional cooperative trial to evaluate the safety of anti-VEGF therapy with concurrent radiation and chemotherapy in any disease site. ${ }^{38}$ This study demonstrated higher than expected rates of toxicity, as $35.4 \%$ of patients experienced Grade 3 or greater treatment-related gastrointestinal (GI) toxicity. It has been speculated that this phenomenon may have been secondary to impairment of normal bowel healing between radiation fractions due to a restriction of physiologic VEGF activity. Additionally, excessive off-protocol inclusion of the bowel within radiation treatment fields has been discussed as a possible contributing factor. It could also be a result of the tendency for advanced pancreatic cancer to involve the duodenum. Overall, the GI toxicity observed in these trials is particularly instructive to radiation oncologists regarding the potential for synergistic GI toxicity when irradiating tumors in the abdomen or pelvis with concurrent bevacizumab. ${ }^{20,34,38}$

In the setting of glioblastoma multiforme (GBM), the recent reports of two randomized trials demonstrated no OS benefit with the addition of bevacizumab to the standard therapy of radiation and temozolomide, despite improvement in PFS. Conflicting results for quality of life and maintenance of performance status were observed, with bevacizumab being beneficial in one trial and harmful in the other. ${ }^{39,40}$ 
Overall, the addition of bevacizumab to standard therapy has resulted in PFS benefits in non-cervical malignancies in both the definitive and metastatic or recurrent setting. However, despite the OS benefits previously observed in metastatic colorectal and lung cancer, no prolongation in OS has ever been reported in a prospective randomized trial evaluating the addition of bevacizumab to a definitive therapy with curative intent.

\section{Bevacizumab for cervical cancer Bevacizumab and anti-angiogenesis for metastatic or recurrent cervical cancer}

Quality trials evaluating bevacizumab's utility against cervical cancer are few in number, though available evidence, reviewed here, indicates activity against this disease, particularly in the metastatic setting. Wright et al reported some of the initial clinical evidence for the efficacy of bevacizumab in cervical cancer. Their retrospective analysis of a small group of six women with metastatic and heavily pre-treated cervical cancer showed a $67 \%$ response rate when combined with cytotoxic chemotherapy. ${ }^{41}$ In this small cohort of patients, bevacizumab was also well-tolerated overall, although one patient developed Grade 4 toxicity (neutropenic sepsis). However, this was most likely attributable to the cytotoxic component of therapy.

Prospective trials of bevacizumab in the treatment of cervical cancer in the metastatic and definitive setting are summarized in Table 2. Monk et al reported the first Phase II trial of bevacizumab in cervical cancer conducted through the GOG. In this trial, bevacizumab was delivered as palliative monotherapy ( $15 \mathrm{mg} / \mathrm{kg}$ every 21 days) to women with recurrent disease who had previously been treated with either one or two regimens of cytotoxic chemotherapy beyond their initial, definitive therapy. ${ }^{42}$ Although it was hypothesized that the antiangiogenic effects may induce cytostasis leading to some interval of stable disease, single-agent bevacizumab induced an objective tumor regression in five patients $(11 \%)$ and eleven patients (24\%) were without progressive disease for at least 6 months. These responses were far better than investigators initially anticipated during the design of the trial. Further, bevacizumab actually outperformed a number of cytotoxic agents when compared against historical singleagent GOG regimens. ${ }^{43-45}$ Toxicities, including hypertension, thromboembolism, and gastroenteritis, were far from benign though, in keeping with bevacizumab use in other disease sites.

Following these single-arm Phase II results, the GOG initiated a randomized Phase III trial (GOG 240) of chemotherapy with and without co-delivery of concurrent bevacizumab. ${ }^{31}$ In this four-arm trial with a $2 \times 2$ factorial design, bevacizumab $(15 \mathrm{mg} / \mathrm{kg})$ was evaluated with and without two separate chemotherapy doublets, either cisplatin plus paclitaxel or topotecan plus paclitaxel. The first planned analysis demonstrated that the topotecancontaining doublet was not superior to the standard doublet with cisplatin. Subsequent analysis on bevacizumab's efficacy was published in manuscript form in February 2014 and revealed a significant OS benefit. The median OS was improved by 3.7 months (17 versus [vs] 13.3 months) for those who received bevacizumab regardless of their concomitant doublet backbone. Response rates were also higher in those patients receiving bevacizumab as a component of therapy ( $48 \%$ vs $36 \%$ ). Toxicity was comparable to other bevacizumab trials, as patients in the bevacizumab arm experienced hypertension (25\% of patients), thromboembolic events ( $8 \%)$, and GI fistulas (3\%) at higher rates. One important criticism of this trial is the selection of cisplatin for the chemotherapy doublet backbone.

Table 2 Selected prospective Phase II and III trials evaluating bevacizumab in cervical malignancies

\begin{tabular}{|c|c|c|c|c|c|c|}
\hline Study & $\mathbf{n}$ & Setting & Design & Bev dose & Toxicity with Bev & Outcomes with Bev \\
\hline Monk et a ${ }^{42}$ & 38 & Metastatic & Phase II. Bev monotherapy & $15 \mathrm{mg} / \mathrm{kg}$ q $21 \mathrm{~d}$ & $\begin{array}{l}\text { Common G3/4 AEs: } \\
\text { HTN (7), TE (5), and GI (5) } \\
\text { One G5 infection }\end{array}$ & $\begin{array}{l}\text { Median PFS } 3.4 \mathrm{~m} \\
\text { Median OS } 7.3 \mathrm{~m} \\
\text { Compared favorably } \\
\text { with historical control }\end{array}$ \\
\hline $\begin{array}{l}\text { Tewari } \\
\text { et al }{ }^{3 !}\end{array}$ & 452 & Metastatic & $\begin{array}{l}\text { Phase III. } 2 \times 2 \text { design } \\
\text { Cisplatin/paclitaxel }+ \text { /- Bev } \\
\text { Topotecan/paclitaxel }+ \text { /- Bev }\end{array}$ & $15 \mathrm{mg} / \mathrm{kg}$ q $21 \mathrm{~d}$ & $\begin{array}{l}\text { More } \geq \mathrm{G} 2 \mathrm{HTN} \\
\text { More } \mathrm{G} 3 / 4 \text { TE and } \mathrm{Gl} \text { fistula }\end{array}$ & $\begin{array}{l}\text { Improved median OS } \\
(17 \text { versus } 13.3 \mathrm{~m})\end{array}$ \\
\hline $\begin{array}{l}\text { Schefter } \\
\text { et } \mathrm{al}^{51,52}\end{array}$ & 49 & Locally advanced & Phase II. Cisplatin/RT + Bev & $\begin{array}{l}10 \mathrm{mg} / \mathrm{kg} \mathrm{q} \mathrm{l} 4 \mathrm{~d} \\
3 \text { doses only }\end{array}$ & $\begin{array}{l}\text { Most common toxicity } \\
\text { hematologic: G3 in } \\
\text { I } 3 \text { patients, G4 in } 5 \text { patients. } \\
\text { No G4/5 Gl AEs }\end{array}$ & $\begin{array}{l}3 \text { y OS } 81.3 \% \\
3 \text { y DFS } 68.7 \% \\
3 \text { y LRF } 23.2 \%\end{array}$ \\
\hline
\end{tabular}

Abbreviations: AEs, adverse events; Bev, bevacizumab; d, days; DFS, disease-free survival; G, Grade; GI, gastrointestinal; HTN, hypertension; LRF, locoregional failure; m, months; OS, overall survival; PFS, progression-free survival; q, every; RT, radiation therapy; TE, thromboembolic event; $y$, years. 
Carboplatin (vs cisplatin) combined with paclitaxel is considered the standard of care based on its more favorable toxicity profile. ${ }^{46}$ However, this marked the first instance of a targeted agent improving OS in a gynecologic malignancy. The OS benefit observed in the initial report of GOG 240 is comparable to those noted previously with bevacizumab in metastatic first- ${ }^{25}$ and second-line ${ }^{26}$ colorectal as well as non-small-cell lung cancer. ${ }^{27}$

Given the aberrant vasculature and hypoxic nature of cervical carcinoma, bevacizumab as well as other targeted agents have been investigated as means to manipulate the angiogenic milieu and limit the propagation of these tumors. Although a full discussion of other antiangiogenic agents is beyond the scope of this review, a few small prospective trials of other antiangiogenics in the setting of metastatic cervical carcinoma have been completed. Sunitinib is an oral agent that targets the VEGF receptor (VEGFR) and was studied in a Phase II trial of metastatic cervical cancer, though no objective responses were seen and unexpectedly high rates of fistula formation were observed. ${ }^{47}$ Pazopanib is an orally administered tyrosine kinase inhibitor (TKI) with activity against multiple variants of VEGFR that has shown some efficacy in a prospective Phase II trial, although PFS improvements were small. ${ }^{48}$ Another small molecule inhibitor, brivanib, induces selective inhibition of both VEGFR and fibroblast growth factor receptor, and while it has shown some promise in the preclinical setting, ${ }^{49}$ early trials demonstrating its clinical efficacy in the treatment of various malignancies are currently ongoing.

\section{Bevacizumab for non-metastatic cervical cancer}

Following the recent publication of GOG 240, we now have evidence of bevacizumab's contribution to improved OS in metastatic cervical cancer. While similar efficacy was demonstrated in metastatic colorectal and lung cancers, subsequent investigation into the utility of bevacizumab for localized disease ultimately failed to demonstrate OS benefits in those disease sites. The answer to this question with respect to cervical cancer remains to be elucidated, as no randomized Phase III trials combining bevacizumab with chemotherapy and radiation have yet been reported for cervical cancer in the definitive setting. However, the RTOG recently reported the initial results of the first single-arm cooperative group Phase II trial (RTOG 0417), which evaluated 49 women with bulky Stage IB-IIIB tumors. The trial was designed to assess toxicity as its primary endpoint. All of these patients had bevacizumab combined with the upfront standard of care, definitive radiotherapy (both external beam whole pelvic radiotherapy and brachytherapy) with concurrent cisplatin.

The selection of bevacizumab dose and schedule in the RTOG 0417 trial merits discussion. In this study, bevacizumab (10 mg/kg every 2 weeks) was delivered for three cycles only, and no maintenance therapy was given. Previously, in their small but pivotal series of rectal cancer patients that did receive concurrent pelvic radiation, Willett et al actually decided on a lower dose ( $5 \mathrm{mg} / \mathrm{kg}$ every 2 weeks) as doselimiting diarrhea and colitis were deemed unacceptable at dose escalation to $10 \mathrm{mg} / \mathrm{kg}$. However, among patients treated with the higher dose of $10 \mathrm{mg} / \mathrm{kg}$, two complete responses in the neoadjuvant treatment of rectal cancer were observed, ${ }^{34}$ indicating that a higher dose may prove efficacious as long as the volume of bowel in the radiation field can be minimized. However, even bevacizumab alone has resulted in substantial bowel toxicity in the treatment of ovarian cancer, though patients with ovarian cancer are at higher risk of experiencing bowel toxicity than patients with cervical cancer. Careful patient selection may minimize toxicity. ${ }^{50}$

In the initial publication of RTOG 0417, the GI toxicity was relatively mild and only two of the 46 patients developed Grade 3 GI adverse events, and no Grade 4 or 5 events were noted. Specifically, there were no GI fistulas or perforations, although advanced cervical cancer differs from ovarian cancer or rectal cancer in that surgery is not generally a component of primary therapy and patients generally experience comparatively less bowel toxicity throughout their treatment course. Hematologic toxicity was the most common among all defined adverse events and the study met its predetermined goals for feasibility and safety. ${ }^{51}$ Two years later, OS, disease-free survival (DFS), and locoregional control were reported. ${ }^{52}$ Three-year OS and DFS in RTOG 0417 were $81.3 \%$ and $68.7 \%$, respectively. Three-year locoregional failure was $23.2 \%$. These outcomes compare favorably with historical reports, although comparison across studies must be made with caution.

Overall, the results of RTOG 0417 demonstrate the feasibility, safety, and encouraging oncologic outcomes with the addition of bevacizumab to standard chemoradiotherapy. Additionally, the authors of the RTOG 0417 report speculated on the implications of the interim analysis of GOG 240. In light of the survival benefit observed in GOG 240 among patients previously treated with chemoradiation, presumably leading to substantial proportions of chemoradiotherapyresistant clonogens, it could be speculated that concurrent plus maintenance bevacizumab administered in conjunction with definitive chemoradiation may convert a portion of the 
patients from partial responders to complete responders in the definitive setting as well. However, this hypothesis will have to be tested in a randomized clinical trial.

\section{Conclusion}

Utilizing the current standard of concurrent chemotherapy and radiation, OS for women with locally advanced disease is approximately $60 \%$ at 5 years. ${ }^{53}$ This remains suboptimal. The addition of bevacizumab to a multimodality approach represents one strategy to improve outcomes, with unique pathway targeting as well as potential synergy with chemoradiotherapy.

The addition of bevacizumab to first-line chemotherapy is now supported by level I evidence of a survival benefit in patients with metastatic and recurrent cervical cancer. Further, the results of RTOG 0417 indicate that bevacizumab may safely be utilized in the non-metastatic setting, concurrently with radiation, as toxicities observed in this trial did not overlap with those previously demonstrated with combination cytotoxic chemotherapy.

However, the clinical enthusiasm for bevacizumab in addition to definitive chemoradiation remains tempered by forerunning clinical experience with bevacizumab in other sites demonstrating OS benefits in the metastatic setting but only PFS benefits in trials in the curative intent setting. Moreover, the current absence of level I evidence to support a survival advantage with the addition of bevacizumab to standard therapy for non-metastatic cervical cancer may generate questions regarding cost-effectiveness when used outside the context of a clinical trial. Further, careful consideration must be given to the unique toxicities that may arise from antiangiogenic therapies and radiation, particularly when treating pelvic and abdominal targets. Patient selection will likely grow in importance as we learn more about this therapy and its interaction with normal tissue and other cytotoxic therapies. Whether it be through the development of predictive biomarkers, ${ }^{54,55}$ individual clinical characteristics, ${ }^{50}$ or even utilizing advanced imaging techniques such as positron emission tomography/computed tomography, ${ }^{56}$ judicious application of bevacizumab and other agents is key to achieving advantageous balance between efficacy and toxicity. Questions also remain about the predictive nature of histologic subtypes outside of squamous cell carcinomas, such as neuroendocrine ${ }^{57,58}$ or adenocarcinomas, where increased MVD and VEGF expression in the latter might suggest an enhanced benefit of bevacizumab targeting..$^{17,18}$

Ultimately, the question of improved survival, and an optimized therapeutic ratio will need to be addressed in the context of a randomized clinical trial. Despite its inherent toxicities and limitations, bevacizumab remains a promising biologic agent with documented success in cervical cancer, as well as in other select disease sites, and oncologists should advocate for its inclusion in further trials in the definitive setting.

\section{Disclosure}

Dr Schefter received a small (US\$1,000) advisory board payment from Genentech Inc. The authors report no other conflicts of interest in this work.

\section{References}

1. Siegel R, Naishadham D, Jemal A. Cancer statistics, 2013. CA Cancer J Clin. 2013;63(1):11-30.

2. Global Cancer Facts and Figures. In: Society AC, ed. 2nd ed. Atlanta, GA: American Cancer Society; 2011.

3. Morris M, Eifel PJ, Lu J, et al. Pelvic radiation with concurrent chemotherapy compared with pelvic and para-aortic radiation for highrisk cervical cancer. N Engl J Med. 1999;340(15):1137-1143.

4. Whitney CW, Sause W, Bundy BN, et al. Randomized comparison of fluorouracil plus cisplatin versus hydroxyurea as an adjunct to radiation therapy in stage IIB-IVA carcinoma of the cervix with negative para-aortic lymph nodes: a Gynecologic Oncology Group and Southwest Oncology Group study. J Clin Oncol. 1999;17(5):1339-1348.

5. Chemoradiotherapy for Cervical Cancer Meta-Analysis Collaboration. Reducing uncertainties about the effects of chemoradiotherapy for cervical cancer: a systematic review and meta-analysis of individual patient data from 18 randomized trials. J Clin Oncol. 2008;26(35): 5802-5812.

6. Carmeliet P. VEGF as a key mediator of angiogenesis in cancer. Oncology. 2005;69 Suppl 3:4-10.

7. Raspollini MR, Amunni G, Villanucci A, Baroni G, Boddi V, Taddei G. Prognostic significance of microvessel density and vascular endothelial growth factor expression in advanced ovarian serous carcinoma. Int $J$ Gynecol Cancer. 2004;14(5):815-823.

8. Dellas A, Moch H, Schultheiss E, et al. Angiogenesis in cervical neoplasia: microvessel quantitation in precancerous lesions and invasive carcinomas with clinicopathological correlations. Gynecol Oncol. 1997;67(1):27-33.

9. Cooper RA, Wilks DP, Logue JP, et al. High tumor angiogenesis is associated with poorer survival in carcinoma of the cervix treated with radiotherapy. Clin Cancer Res. 1998;4(11):2795-2800.

10. Byrne AM, Bouchier-Hayes DJ, Harmey JH. Angiogenic and cell survival functions of vascular endothelial growth factor (VEGF). $J$ Cell Mol Med. 2005;9(4):777-794.

11. Hicklin DJ, Ellis LM. Role of the vascular endothelial growth factor pathway in tumor growth and angiogenesis. $J$ Clin Oncol. 2005;23(5):1011-1027.

12. Goel S, Duda DG, Xu L, et al. Normalization of the vasculature for treatment of cancer and other diseases. Physiol Rev. 2011;91(3): 1071-1121.

13. Walboomers JM, Jacobs MV, Manos MM, et al. Human papillomavirus is a necessary cause of invasive cervical cancer worldwide. J Pathol. 1999;189(1):12-19.

14. Birner P, Schindl M, Obermair A, Plank C, Breitenecker G, Oberhuber G. Overexpression of hypoxia-inducible factor 1alpha is a marker for an unfavorable prognosis in early-stage invasive cervical cancer. Cancer Res. 2000;60(17):4693-4696.

15. Mukhopadhyay D, Tsiokas L, Sukhatme VP. Wild-type p53 and v-Src exert opposing influences on human vascular endothelial growth factor gene expression. Cancer Res. 1995;55(24):6161-6165. 
16. Farhang Ghahremani M, Goossens $\mathrm{S}$, Nittner D, et al. p53 promotes VEGF expression and angiogenesis in the absence of an intact $\mathrm{p} 21-\mathrm{Rb}$ pathway. Cell Death Differ. 2013;20(7):888-897.

17. Tokumo K, Kodama J, Seki N, et al. Different angiogenic pathways in human cervical cancers. Gynecol Oncol. 1998;68(1):38-44.

18. Eifel PJ, Burke TW, Morris M, Smith TL. Adenocarcinoma as an independent risk factor for disease recurrence in patients with stage IB cervical carcinoma. Gynecol Oncol. 1995;59(1):38-44.

19. Dobbs SP, Hewett PW, Johnson IR, Carmichael J, Murray JC. Angiogenesis is associated with vascular endothelial growth factor expression in cervical intraepithelial neoplasia. Br J Cancer. 1997; 76(11):1410-1415.

20. Jain RK. Normalization of tumor vasculature: an emerging concept in antiangiogenic therapy. Science. 2005;307(5706):58-62.

21. Jain RK, Duda DG, Clark JW, Loeffler JS. Lessons from phase III clinical trials on anti-VEGF therapy for cancer. Nat Clin Pract Oncol. 2006;3(1):24-40.

22. Lee CG, Heijn M, di Tomaso E, et al. Anti-vascular endothelial growth factor treatment augments tumor radiation response under normoxic or hypoxic conditions. Cancer Res. 2000;60(19):5565-5570.

23. Teicher BA, Dupuis N, Kusomoto T, et al. Antiangiogenic agents can increase tumor oxygenation and response to radiation therapy. Radiat Oncol Invest. 1994;2(6):269-276.

24. Willett CG, Boucher Y, di Tomaso E, et al. Direct evidence that the VEGF-specific antibody bevacizumab has antivascular effects in human rectal cancer. Nat Med. 2004;10(2):145-147.

25. Hurwitz H, Fehrenbacher L, Novotny W, et al. Bevacizumab plus irinotecan, fluorouracil, and leucovorin for metastatic colorectal cancer. N Engl J Med. 2004;350(23):2335-2342.

26. Giantonio BJ, Catalano PJ, Meropol NJ, et al. Bevacizumab in combination with oxaliplatin, fluorouracil, and leucovorin (FOLFOX4) for previously treated metastatic colorectal cancer: results from the Eastern Cooperative Oncology Group Study E3200. J Clin Oncol. 2007;25(12):1539-1544.

27. Sandler A, Gray R, Perry MC, et al. Paclitaxel-carboplatin alone or with bevacizumab for non-small-cell lung cancer. $N$ Engl $J$ Med. 2006;355(24):2542-2550.

28. Miller K, Wang M, Gralow J, et al. Paclitaxel plus bevacizumab versus paclitaxel alone for metastatic breast cancer. $N$ Engl $J$ Med. 2007;357(26):2666-2676.

29. Kindler HL, Niedzwiecki D, Hollis D, et al. Gemcitabine plus bevacizumab compared with gemcitabine plus placebo in patients with advanced pancreatic cancer: phase III trial of the Cancer and Leukemia Group B (CALGB 80303). J Clin Oncol. 2010;28(22): $3617-3622$.

30. Van Cutsem E, Vervenne WL, Bennouna J, et al. Phase III trial of bevacizumab in combination with gemcitabine and erlotinib in patients with metastatic pancreatic cancer. J Clin Oncol. 2009;27(13): 2231-2237.

31. Tewari KS, Sill MW, Long HJ 3rd, et al. Improved survival with bevacizumab in advanced cervical cancer. $N$ Engl $J$ Med. 2014;370(8):734-743.

32. Burger RA, Sill MW, Monk BJ, Greer BE, Sorosky JI. Phase II trial of bevacizumab in persistent or recurrent epithelial ovarian cancer or primary peritoneal cancer: a Gynecologic Oncology Group Study. J Clin Oncol. 2007;25(33):5165-5171.

33. Perren TJ, Swart AM, Pfisterer J, et al; ICON7 Investigators. A phase 3 trial of bevacizumab in ovarian cancer. $N$ Engl $J$ Med. 2011;365(26):2484-2496.

34. Willett CG, Boucher Y, Duda DG, et al. Surrogate markers for antiangiogenic therapy and dose-limiting toxicities for bevacizumab with radiation and chemotherapy: continued experience of a phase I trial in rectal cancer patients. J Clin Oncol. 2005;23(31):8136-8139.

35. Willett CG, Duda DG, di Tomaso E, et al. Efficacy, safety, and biomarkers of neoadjuvant bevacizumab, radiation therapy, and fluorouracil in rectal cancer: a multidisciplinary phase II study. J Clin Oncol. 2009;27(18):3020-3026.
36. Allegra CJ, Yothers G, O'Connell MJ, et al. Initial safety report of NSABP C-08: a randomized phase III study of modified FOLFOX6 with or without bevacizumab for the adjuvant treatment of patients with stage II or III colon cancer. J Clin Oncol. 2009;27(20): 3385-3390.

37. Crane $\mathrm{CH}$, Ellis LM, Abbruzzese JL, et al. Phase I trial evaluating the safety of bevacizumab with concurrent radiotherapy and capecitabine in locally advanced pancreatic cancer. J Clin Oncol. 2006;24(7): $1145-1151$.

38. Crane $\mathrm{CH}$, Winter K, Regine WF, et al. Phase II study of bevacizumab with concurrent capecitabine and radiation followed by maintenance gemcitabine and bevacizumab for locally advanced pancreatic cancer: Radiation Therapy Oncology Group RTOG 0411. J Clin Oncol. 2009; 27(25):4096-4102.

39. Chinot OL, Wick W, Mason W, et al. Bevacizumab plus radiotherapy-temozolomide for newly diagnosed glioblastoma. N Engl J Med. 2014;370(8):709-722.

40. Gilbert MR, Dignam JJ, Armstrong TS, et al. A randomized trial of bevacizumab for newly diagnosed glioblastoma. $N$ Engl $J$ Med. 2014;370(8):699-708.

41. Wright JD, Viviano D, Powell MA, et al. Bevacizumab combination therapy in heavily pretreated, recurrent cervical cancer. Gynecol Oncol. 2006;103(2):489-493.

42. Monk BJ, Sill MW, Burger RA, Gray HJ, Buekers TE, Roman LD. Phase II trial of bevacizumab in the treatment of persistent or recurrent squamous cell carcinoma of the cervix: a Gynecologic Oncology Group Study. J Clin Oncol. 2009;27(7):1069-1074.

43. Rose PG, Blessing JA, Mayer AR, Homesley HD. Prolonged oral etoposide as second-line therapy for platinum-resistant and platinumsensitive ovarian carcinoma: a Gynecologic Oncology Group study. J Clin Oncol. 1998;16(2):405-410.

44. Bookman MA, Blessing JA, Hanjani P, Herzog TJ, Andersen WA. Topotecan in squamous cell carcinoma of the cervix: a phase II study of the Gynecologic Oncology Group. Gynecol Oncol. 2000;77(3): 446-449.

45. Mannel RS, Blessing JA, Boike G. Cisplatin and pentoxifylline in advanced or recurrent squamous cell carcinoma of the cervix: a phase II trial of the Gynecologic Oncology Group. Gynecol Oncol. 2000;79(1):64-66.

46. Kitagawa R, Katsumata N, Shibata T, et al. A randomized, phase III trial of paclitaxel plus carboplatin (TC) versus paclitaxel plus cisplatin (TP) in stage IVb, persistent or recurrent cervical cancer: Japan Clinical Oncology Group study (JCOG0505). J Clin Oncol. 2012;30 Suppl: Abst 5006.

47. Mackay HJ, Tinker A, Winquist E, et al. A phase II study of sunitinib in patients with locally advanced or metastatic cervical carcinoma: NCIC CTG Trial IND.184. Gynecol Oncol. 2010;116(2):163-167.

48. Monk BJ, Pandite LN. Survival data from a phase II, open-label study of pazopanib or lapatinib monotherapy in patients with advanced and recurrent cervical cancer. J Clin Oncol. 2011;29(36):4845.

49. Bhide RS, Lombardo LJ, Hunt JT, et al. The antiangiogenic activity in xenograft models of brivanib, a dual inhibitor of vascular endothelial growth factor receptor-2 and fibroblast growth factor receptor-1 kinases. Mol Cancer Ther. 2010;9(2):369-378.

50. Simpkins F, Belinson JL, Rose PG. Avoiding bevacizumab related gastrointestinal toxicity for recurrent ovarian cancer by careful patient screening. Gynecol Oncol. 2007;107(1):118-123.

51. Schefter TE, Winter K, Kwon JS, et al. A phase II study of bevacizumab in combination with definitive radiotherapy and cisplatin chemotherapy in untreated patients with locally advanced cervical carcinoma: preliminary results of RTOG 0417 . Int J Radiat Oncol Biol Phys. 2012;83(4):1179-1184.

52. Schefter T, Winter K, Kwon JS, et al; Radiation Therapy Oncology Group (RTOG). RTOG 0417: efficacy of bevacizumab in combination with definitive radiation therapy and cisplatin chemotherapy in untreated patients with locally advanced cervical carcinoma. Int J Radiat Oncol Biol Phys. 2014;88(1):101-105. 
53. Eifel PJ, Winter K, Morris M, et al. Pelvic irradiation with concurrent chemotherapy versus pelvic and para-aortic irradiation for high-risk cervical cancer: an update of radiation therapy oncology group trial (RTOG) 90-01. J Clin Oncol. 2004;22(5):872-880.

54. Jubb AM, Harris AL. Biomarkers to predict the clinical efficacy of bevacizumab in cancer. Lancet Oncol. 2010;11(12):1172-1183.

55. Lambrechts D, Lenz HJ, de Haas S, Carmeliet P, Scherer SJ. Markers of response for the antiangiogenic agent bevacizumab. J Clin Oncol. 2013;31(9):1219-1230.

56. Kidd EA, Siegel BA, Dehdashti F, Grigsby PW. Pelvic lymph node F-18 fluorodeoxyglucose uptake as a prognostic biomarker in newly diagnosed patients with locally advanced cervical cancer. Cancer. 2010;116(6):1469-1475.
57. Kulke MH, Stuart K, Earle CC, et al. A phase II study of temozolomide and bevacizumab in patients with advanced neuroendocrine tumors. J Clin Oncol. 2006;24 Suppl 18:Abst 4044.

58. Venook AP, Ko AH, Tempero MA, et al. Phase II trial of FOLFOX plus bevacizumab in advanced, progressive neuroendocrine tumors. J Clin Oncol. 2008;26 Suppl 15:Abst 15545.

\section{Publish your work in this journal}

OncoTargets and Therapy is an international, peer-reviewed, open access journal focusing on the pathological basis of all cancers, potential targets for therapy and treatment protocols employed to improve the management of cancer patients. The journal also focuses on the impact of management programs and new therapeutic agents and protocols on

\section{Dovepress}

patient perspectives such as quality of life, adherence and satisfaction The manuscript management system is completely online and includes a very quick and fair peer-review system, which is all easy to use. Visit http://www.dovepress.com/testimonials.php to read real quotes from published authors.

\footnotetext{
Submit your manuscript here: http://www.dovepress.com/oncotargets-and-therapy-journal
} 